\title{
Desmodesmus subspicatus co-cultured with microcystin producing (PCC 7806) and the non-producing (PCC 7005) strains of Microcystis aeruginosa
}

\author{
Azam Omidi $\mathbb{D}^{1} \cdot$ Maranda Esterhuizen-Londt $\mathbb{\mathbb { D }}^{2,3,4} \cdot$ Stephan Pflugmacher $\mathbb{C}^{2,3,4}$
}

Accepted: 15 July 2019 / Published online: 27 July 2019

(c) The Author(s) 2019

\begin{abstract}
Although microcystins (MCs) are the most commonly studied cyanotoxins, their significance to the producing organisms remains unclear. MCs are known as endotoxins, but they can be found in the surrounding environment due to cell lysis, designated as extracellular MCs. In the present study, the interactions between MC producing and the non-producing strains of Microcystis aeruginosa, PCC 7806 and PCC 7005, respectively, and a green alga, Desmodesmus subspicatus, were studied to better understand the probable ecological importance of MCs at the collapse phase of cyanobacterial blooms. We applied a dialysis co-cultivation system where $M$. aeruginosa was grown inside dialysis tubing for one month. Then, $D$. subspicatus was added to the culture system on the outside of the membrane. Consequently, the growth of D. subspicatus and MC contents were measured over a 14-day co-exposure period. The results showed that Microcystis negatively affected the green alga as the growth of D. subspicatus was significantly inhibited in co-cultivation with both the MC-producing and -deficient strains. However, the inhibitory effect of the MC-producing strain was greater and observed earlier compared to the MC-deficient strain. Thus, MCs might be considered as an assistant factor that, in combination with other secondary metabolites of Microcystis, reinforce the ability to outcompete co-existing species.
\end{abstract}

Keywords Co-cultivation $\cdot D$. subspicatus $\cdot M$. aeruginosa $\cdot$ MC-LR $\cdot$ Interspecies interactions

\section{Introduction}

In recent decades, the increasing occurrence of cyanobacterial blooms in water bodies throughout the world has raised concerns (Buratti et al. 2017; Svirčev et al. 2017). Moreover, global warming and eutrophication have

Stephan Pflugmacher

stephan.pflugmacher@helsinki.fi

1 Technische Universität Berlin, Chair Ecological Impact Research and Ecotoxicology, Ernst-Reuter-Platz 1, 10587 Berlin, Germany

2 University of Helsinki, Aquatic Ecotoxicology in an Urban Environment, Ecosystems and Environment Research Programme, Faculty of Biological and Environmental Sciences, Niemenkatu 73, 15140 Lahti, Finland

3 Korean Institute of Science and Technology Europe (KIST), Joint laboratory of Applied Ecotoxicology, Campus E7 1, 66123 Saarbrücken, Germany

4 Helsinki Institute of Sustainability (HELSUS), Fabianinkatu 33, 00014 Helsinki, Finland increased the occurrence of cyanobacterial blooms with a shift toward more toxic populations (Dziallas and Grossart 2011; Scholz et al. 2017). Cyanobacteria are known to produce toxic secondary metabolites designated as cyanotoxins which have undesirable effects on humans, animals, and aquatic organisms (Catherine et al. 2013; Zanchett and Oliveira-Filho 2013; Lévesque et al. 2014). Among the cyanotoxins, microcystins (MCs) are the most commonly studied. However, past studies have mainly focused on the toxicity of MCs while their importance to the producing organisms is still unknown. Recently, there has been a considerable growing interest in understanding the physiological and ecological importance of MCs to the producers beyond their toxicity.

MCs are produced by many species of cyanobacteria, however the most common bloom-forming species is Microcystis aeruginosa (Carmichael 1992). They are highcost products which are synthesised non-ribosomally via a complex multifunctional enzyme, MC synthetase (Nishizawa et al. 2000; Welker and Von Döhren 2006). It is still uncertain why producers pay such a high energy price for 
the synthesis of MCs. A study by Christiansen et al. (2008) revealed that non-toxic strains could produce other nonribosomal peptides, but not MC variants due to the partial or total lack of the MC synthetase genes, mcy gene cluster. MC-deficient strains, therefore, can be useful tools in competitive studies with toxic strains, to clarify the importance of MCs for the producing species. Previous studies demonstrated that MC-producing strains gain advantages from MC production over non-toxic subpopulations for better environmental adaptations under low or high light irradiation (Renaud et al. 2011), C-limited conditions (Jähnichen et al. 2007; Zhang et al. 2012), and elevated water temperature (Dziallas and Grossart 2011).

Recent studies have suggested some ecological and physiological functions for MCs; varying from the interference in photosynthesis and nutrient metabolism to quorum sensing, iron uptake, recruitment, defence against grazers, and allelopathic interactions (Omidi et al. 2017). The toxin-related interspecies interactions between Microcystis and other co-existing organisms such as the members of the phytoplankton community may further elucidate the ecological importance of MCs.

Toxin production by M. aeruginosa has been suggested to be a continuous process that starts in the early logarithmic phase to the beginning of the stationary phase (Lyck 2004; Jähnichen et al. 2008). MCs can be enclosed within the cells (intracellular MCs) or released into surrounding water (extracellular MCs) (Sivonen and Jones 1999) at different growth stages and under various environmental or physiological conditions, by cell lysis or leakage of intracellular MCs (Rapala et al. 1997; Leflaive and Ten-Hage 2007). Varying levels of MCs have been detected in the water bodies ranging from $<3 \mu \mathrm{g} \mathrm{L}^{-1}$ across Europe to $19,500 \mu \mathrm{g} \mathrm{L}^{-1}$ in water samples from Japan (Turner et al. 2018). During senescence of scums or very dense cyanobacterial blooms, high concentrations of MC reaching up to $25,000 \mu \mathrm{g} \mathrm{L}^{-1}$ have been reported (Sivonen and Jones 1999; World Health Organization 2003).

When blooms collapse due to artificial (mechanical or chemical) or natural processes, the cellular material containing high concentrations of toxins are released into the environments in a short period. In nature, the toxin concentrations do not stay at these high level indefinitely due to rapid dilution in the water column and degradation of MCs by light or certain species of bacteria (Christoffersen et al. 2002; Gagała and Mankiewicz-Boczek 2012). However, before this happens, aquatic biota is constantly exposed to MCs for days (Jones and Orr 1994).

In aquatic habitats, the cyanobacterial blooms are frequently associated with green algae, another member of the phytoplankton community (Sedmak and Kosi 1998; Paerl et al. 2001). The phytoplankton community, contain other members such as diatoms, dinoflagellates, and a diverse group of algae as well (Reynolds 2006). The species composition of phytoplankton communities are dynamic and change in seasonal cycles, a phenomenon called seasonal successions where according to the seasonal pattern the species dominate the phytoplankton community in successive waves (Reynolds 1980; Sedmak and Kosi 1998; Chen et al. 2003; El Herry et al. 2008). Past studies have shown that not only the abiotic environmental conditions, but also the biological factors such as interspecies interferences, influenced the seasonal fluctuations of the algal populations in the phytoplankton community (Vardi et al. 2002; Chen et al. 2003; Legrand et al. 2003; Granéli and Hansen 2006; Leão et al. 2009; Zhang et al. 2015).

Therefore, the present study aimed to understand the influence and possible advantage of toxin production better, i.e. if it provided a competitive advantage to the MCproducing strain of $M$. aeruginosa. A comparative study between toxic (MC-producing) and non-toxic (MC-deficient) strains of M. aeruginosa, and Desmodesmus subspicatus, a freshwater green alga, was performed in a coexposure system to explore the probable importance of the cyanobacterial bioactive metabolites, especially MCs, when the bloom material starts to lyse, and a high concentration of toxin is released into the surrounding environment.

\section{Materials and methods}

\section{Organisms and culture conditions}

Axenic cultures of M. aeruginosa PCC 7806 and M. aeruginosa PCC 7005 were obtained from the Pasteur Culture Collection of Cyanobacteria (PCC), Paris, France. The green alga, D. subspicatus SAG 86.81 (formerly Scenedesmus subspicatus), was provided by the SAG Culture Collection of Algae (Sammlung von Algenkulturen), University of Göttingen, Germany. The species were grown in BG-11 liquid medium (Rippka et al. 1979) at $24 \pm 1^{\circ} \mathrm{C}$ under an illumination intensity of $2220 \mathrm{~lm} \mathrm{~m}^{-2}$, provided by cool white fluorescent irradiation, with a 12:12 light: dark interval. The growth phases of M. aeruginosa PCC 7806 and PCC 7005 were studied and documented prior to experimentation (Fig. 1c).

\section{Co-cultivation experimental design}

The dialysis membranes with a molecular weight cut-off of 12-14 kDa and diameter of $29 \mathrm{~mm}$ (Spectra/ Por ${ }^{\oplus}$, Spectrum Laboratories, USA) were used to separate the cultures. The membranes were cut into $30 \mathrm{~cm}$ lengths and soaked in distilled water for $15 \mathrm{~min}$. Then, they were incubated in $10 \mathrm{mM}$ sodium bicarbonate $\left(\mathrm{NaHCO}_{3}\right)$ for $30 \mathrm{~min}$ at $80{ }^{\circ} \mathrm{C}$ and soaked in $10 \mathrm{mM} \mathrm{Na}{ }_{2}$ EDTA for $30 \mathrm{~min}$. The wide-open 
Fig. 1 The growth of $D$. subspicatus SAG 86.81 on the outside of the dialysis tubing in co-cultivation with $M$.

aeruginosa $\mathbf{a}$, the density of $M$. aeruginosa 7806 inside of the dialysis tubing in co-cultivation with $D$. subspicatus $\mathbf{b}$, and the growth curves of $M$. aeruginosa PCC 7806 and PCC 7005 c (initial, 1-month-old monoculture of $M$. aeruginosa PCC 7806; C 1: control 1, 6 weeks old monoculture of $M$. aeruginosa PCC 7806; C 2: control 2, monoculture of $D$. subspicatus; $\mathrm{T} 1$ : treatment 1 , co-culture of $M$. aeruginosa PCC 7806 with D. subspicatus; $\mathrm{T} 2$ : treatment 2, co-culture of M. aeruginosa PCC 7005 with D. subspicatus). Data represent mean values \pm standard deviation $(n=3)$. Significant differences observed at $p$-values of $* p<0.001, * * p \leq 0.01$ and $* * * p<0.05$
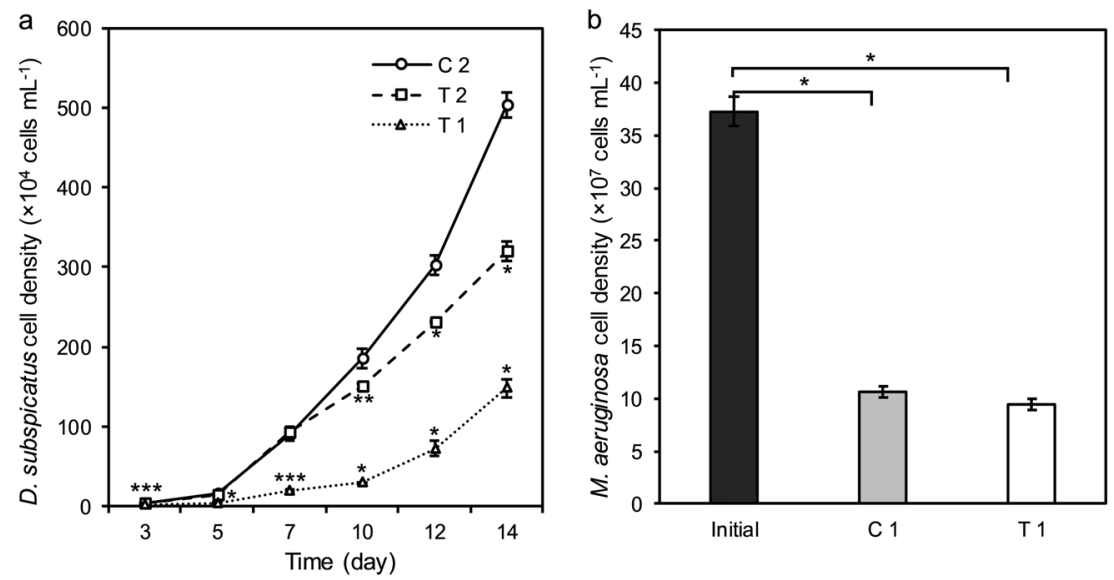

C

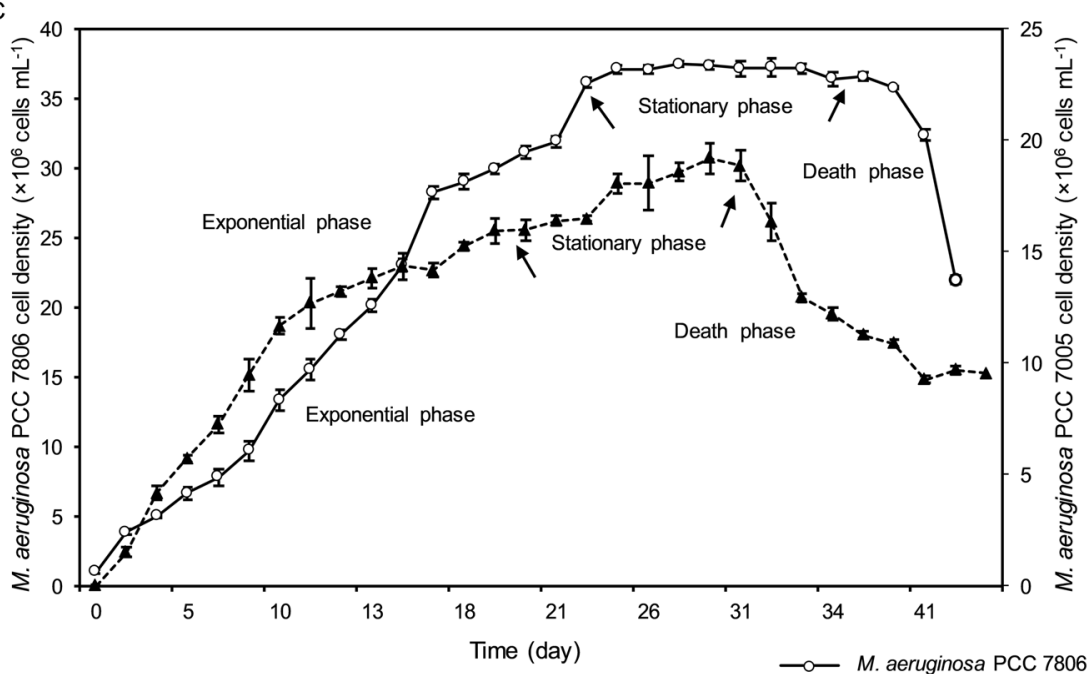

--₫-- M. aeruginosa PCC 7005 end of a glass pasture pipette was used to hold the dialysis tube and to transfer the Microcystis inoculum into the tubing. One end of the membrane was tightly tied to the pasture pipette with a piece of string, as an open end to the latter injection of the cells into the dialysis tubing. Another end was tied closed by a knot, then fastened to the glass pipette with the string. The prepared tubings were autoclaved for $10 \mathrm{~min}$ at $121{ }^{\circ} \mathrm{C}$ and placed aseptically in a $250 \mathrm{~mL}$ glass bottle containing $180 \mathrm{~mL}$ sterile BG-11 medium. The dialysis tubings were filled with $15 \mathrm{~mL}$ fresh sterilized BG-11 medium and Microcystis inoculum in $5 \mathrm{~mL}$ fresh BG-11 medium was injected into the dialysis tubing using a sterile syringe.

Monocultures of $M$. aeruginosa in the dialysis tubing, containing $20 \mathrm{~mL}$ fresh, sterilised BG-11 medium, nine replicates of $M$. aeruginosa PCC 7806 (MC-producing strain), and three replicates of M. aeruginosa PCC 7005 (MC-deficient strain), were prepared each at the initial cell density of $1 \times 10^{7}$ cells $\mathrm{mL}^{-1}$. Then, the groups of toxic and non-toxic independent replicates were grown for 1 month before commencing with the co-cultivation experiments.
Every 5 days, $5 \mathrm{~mL}$ of fresh sterilized BG-11 medium was added out of the membrane.

After 1 month, monocultures of the toxic strain (triplicate) was harvested as 'initial' to measure the initial concentrations of the intracellular and extracellular MC-LR before the introduction of the green algae into the culture system.

The co-cultivation experiments then commenced, i.e. they were performed using 1-month-old monocultures of toxic and non-toxic Microcystis (six and three replicates, respectively). D. subspicatus at the initial density of $1 \times 10^{4}$ cells $\mathrm{mL}^{-1}$ was inoculated on the outside of the membrane into the bottle containing the 1-month-old Microcystis inside the dialysis membrane. As a control for the growth of the green alga, D. subspicatus was cultured in the bottle containing a dialysis tubing that was filled only with BG-11 medium without $M$. aeruginosa. The prepared cultures include 1-month-old monoculture of toxic Microcystis (control 1: C 1), co-cultures of green alga with the toxic (treatment 1: T 1) and non-toxic (treatment 2: T 2) strains of Microcystis, and monoculture of green alga (control 2: C 2), 
were kept on a shaker at $75 \mathrm{rpm}$ under the same conditions as described for the unialgal cultures for 14 days.

\section{Growth measurement of $D$. subspicatus and $M$. aeruginosa PCC 7806}

Every 2 or 3 days, $1 \mathrm{~mL}$ of sample was taken from the outside of the dialysis tubing from each replicate of monocultures (C 2) and co-cultures of the green alga with toxic and non-toxic strains of $M$. aeruginosa (T 1 and T 2, respectively). Then, cells of $D$. subspicatus were counted using bright field microscopy (Olympus CH-2, Japan) and a Neubauer counting chamber (Roth, Karlsruhe, Germany).

The cell density of M. aeruginosa PCC 7806 was monitored in 1-month-old monoculture (initial) and after 2 weeks co-cultivation from mono- (C 1) and co-cultures of toxic Microcystis with green alga (T 1). A $1 \mathrm{~mL}$ sample was collected from the inside of dialysis tubing from each replicate. The optical density of samples $\left(\mathrm{OD}_{750}\right)$ was measured using a spectrophotometer (UVIKON 922, France). Then, the cell numbers was calculated using the calibration curve from the $\mathrm{OD}_{750}$ vs cells $\mathrm{mL}^{-1}$.

\section{Extracellular MC-LR preparation}

Samples from the inside $(5 \mathrm{~mL})$ and outside $(40 \mathrm{~mL})$ of the dialysis tubing were collected from the 1-month-old monoculture of toxic Microcystis (initial) and after 2 weeks co-cultivation from mono- (C 1) and co-cultures of toxic Microcystis with green alga (T 1). Microcystis cells were harvested and the supernatant collected from the inner membrane after centrifugation at $4000 \times g$ for $30 \mathrm{~min}\left(4^{\circ} \mathrm{C}\right)$. The supernatant was collected from the outer side of the membrane after centrifugation $\left(4000 \times g, 15 \mathrm{~min}, 4^{\circ} \mathrm{C}\right)$. The supernatants were filtered through a $0.22 \mu \mathrm{m}$ Whatman filter (Millipore). Solid-phase extraction (SPE) was performed using C18 SPE cartridges (Sep-Pak tC18 6 cc Vac Cartridge, $500 \mathrm{mg}$ Sorbent per Cartridge, pore size $125 \AA$, particle size $37-55 \mu \mathrm{m}$, hold up volume, Waters) which was conditioned with $10 \mathrm{~mL}$ of $100 \%$ methanol $(\mathrm{MeOH})$ and subsequently washed with $10 \mathrm{~mL}$ of distilled water. The cell-free supernatants were applied to the pre-conditioned cartridge and eluted with $10 \mathrm{~mL}$ of $100 \% \mathrm{MeOH}$. The eluent was dried in a concentrator plus (Eppendorf, Germany) at $30^{\circ} \mathrm{C}$, and the residue was resuspended in $1 \mathrm{~mL}$ of $\mathrm{MeOH} 100 \%$ and stored at $-20^{\circ} \mathrm{C}$ until analysis.

\section{Intracellular MC-LR extraction}

Samples of 1-month-old monoculture of toxic Microcystis (initial), and 2 weeks mono- (C 1) and co-cultures of toxic Microcystis with green alga ( $\mathrm{T} 1$ ) were collected from the inside of the dialysis tubing and were centrifuged $(4000 \times \mathrm{g}$, $\left.30 \mathrm{~min}, 4^{\circ} \mathrm{C}\right)$. Then, the pellet was freeze-dried using an LIO-5P freeze dryer (5 pascals, Italy). The lyophilised cells $(25 \mathrm{mg})$ were sonicated in an ultrasonic bath (Allpax, Germany) for $15 \mathrm{~min}$ in 3 cycles of $5 \mathrm{~min}$. After that, intracellular MC-LR was extracted by addition of $1 \mathrm{~mL}$ of $70 \%$ methanol $(\mathrm{MeOH})$ acidified with $0.1 \%$ trifluoroacetic acid (TFA) which was continuously shaken (Intelli-mixer, neo$\mathrm{Lab}^{\circledR}$ ) for $1 \mathrm{~h}$. The resulting supernatant was collected after centrifugation $\left(10,000 \times g, 10 \mathrm{~min}, 4^{\circ} \mathrm{C}\right)$, and the pellet was re-extracted with the same procedure. This procedure was repeated four times. Then, the combined supernatant was evaporated to dryness at $30{ }^{\circ} \mathrm{C}$ using a concentrator plus (Eppendorf, Germany) and the dried material was dissolved in $1 \mathrm{~mL}$ of $100 \% \mathrm{MeOH}$ and centrifuged $(20,800 \times g$, $15 \mathrm{~min}, 4^{\circ} \mathrm{C}$ ). The supernatant was stored at $-20^{\circ} \mathrm{C}$ until analysis by liquid chromatography-tandem mass spectroscopy (LC-MS/MS).

\section{MC-LR analysis}

An Alliance 2695 UHPLC coupled to a Micromass Quattro micro $^{\mathrm{TM}}$ (Waters, Milford, MA, USA) was used for determination and quantification of MC-LR. A reversed phase column Kinetex ${ }^{\mathrm{TM}} \mathrm{C} 18$ column $(2.1 \times 50 \mathrm{~mm}, 2.6 \mu \mathrm{m}$ pore size, Phenomenex) was used for chromatography. Solution A (MS-grade water containing $0.1 \%$ trifluoroacetic acid (TFA) and 5\% acetonitrile (ACN)) and solution B (ACN containing $0.1 \%$ TFA) was used as the mobile phase at a flow rate of $0.2 \mathrm{~mL} \mathrm{~min}^{-1}$. A linear gradient elution program was applied as follows: $0 \mathrm{~min} 100 \% \mathrm{~A} ; 3.75-7 \mathrm{~min}$ $35 \% \mathrm{~A}$, and $7.8-12 \min 100 \% \mathrm{~A}$. The column oven temperature was set at $40{ }^{\circ} \mathrm{C}$. The injection volume was $20 \mu \mathrm{L}$. MC-LR in the samples was identified by the retention time at $7.95 \mathrm{~min}$.

The tandem mass spectroscopy, using electrospray ionization (ESI), conditions were set as follows: the spray voltage was set at $3 \mathrm{kV}$, and the cone voltage at $60 \mathrm{~V}$. The capillary temperature was set at $120^{\circ} \mathrm{C}$, the desolvation gas temperature and cone gas flow-rate was set at $500{ }^{\circ} \mathrm{C}$ and $1000 \mathrm{~L} \mathrm{~h}^{-1}$, respectively. The collision energy was 65 and cone gas flow-rate of $100 \mathrm{~L} \mathrm{~h}^{-1}$. The trigger gas and the collision gas were nitrogen and Argon, respectively. Parent compounds and its fragment ions, respectively, were analysed according to their alignment at the following mass-tocharge ratio $(\mathrm{m} / \mathrm{z}) 995.5 \rightarrow 135.1$.

The detection limit of MC-LR was $1 \mathrm{ng} \mathrm{mL}^{-1}$ (signal to noise $\mathrm{S} / \mathrm{N}>3$ ), and the limit of quantification was set at $5 \mathrm{ng} \mathrm{mL}^{-1}$ (signal to noise the $\mathrm{S} / \mathrm{N}>5$ ). The toxin content was quantified by calibrating against the standard solution of purified solid MC-LR (Enzo, Germany) in $\mathrm{MeOH} 100 \%$. 
Fig. 2 The concentration of a total extracellular MC-LR $\left(\mu \mathrm{g} \mathrm{L}{ }^{-1}\right)$ and b intracellular MC-LR ( $\mu \mathrm{g} \mathrm{g}^{-1}$ dry weight) where initial is the monoculture of $M$. aeruginosa PCC 7806 sampled after 1 month, $\mathrm{C} 1$ is the monoculture of $M$. aeruginosa

PCC7806 sampled 14 days after inception of co-cultivation experiment (6 weeks), and T 1 is the co-culture of $M$. aeruginosa PCC 7806 with green alga-after 14 days. Data represent mean values \pm standard deviation $(n=$ 3 ). Asterisk indicates significant differences at a $p$-value of $p \leq$ 0.001

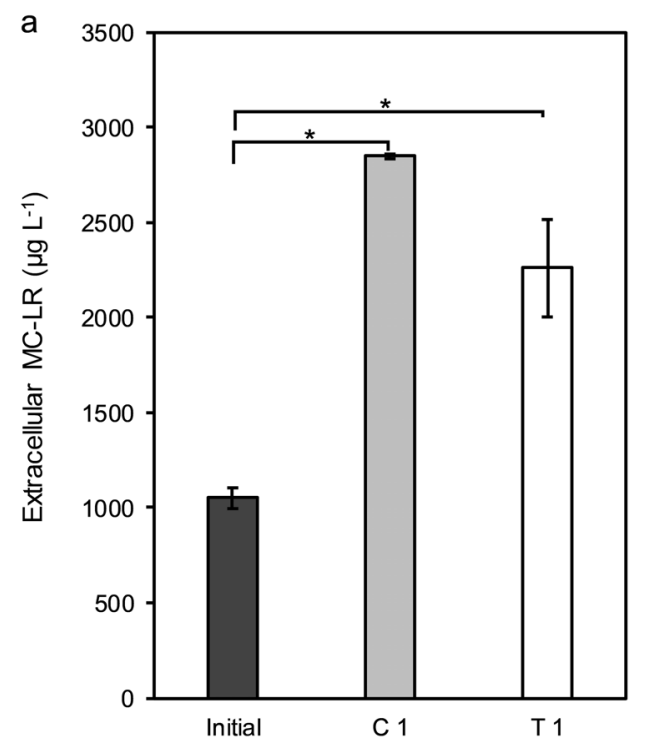

\section{Statistical analysis}

Statistical analyses were performed with SPSS (version 24). Data were tested for normality and homogeneity of variance using the Shapiro-Wilk test and Levene test, respectively. Differences between samples were determined using oneway analyses of variance (ANOVA) followed by Turkey HSD analysis and Student's $t$ test for the homogenous (the growth of D. subspicatus and M. aeruginosa 7806, intracellular MC-LR, and the diffusion rate of extracellular MCLR) and heterogeneous variables (extracellular MC-LR), respectively $(p \leq 0.05)$. Data, which did not follow a normal distribution (growth of $D$. subspicatus on the 3rd day (treatments (T1 and T2), and the 7th day (treatment with $M$. aeruginosa PCC 7806 (T1)) was analysed with nonparametric tests, such as the Kruskal Wallis and Mann-Whitney-U-test.

\section{Results}

\section{Inhibition of growth rate}

After co-cultivation with the MC-producing Microcystis (treatment $1, \mathrm{~T} 1$ ), the biomass of $D$. subspicatus was significantly decreased compared to the biomass concentration achieved in monoculture (C 2) and also co-culture with the MC-deficient strain (treatment 2, T 2) $(p<0.05$, Fig. 1a). The results indicated a long lag phase, from day 3 to 10 , in the growth of green alga co-cultivated with PCC 7806 . After 10 days, the density of green alga in co-cultivation with PCC 7806, sharply levelled off to $29 \times 10^{4}$ cells $\mathrm{mL}^{-1}$, 6.3 and 5.1 times less than when grown as mono- or in coculture with the MC-deficient strain, respectively $(p<$
0.001). Afterwards, the growth of the green alga slowly increased and reached $148 \times 10^{4} \pm 12 \times 10^{4}$ cells mL ${ }^{-1}$ on day 14 , which was 3.4 times less than in monoculture and 2.16 times lower than when co-cultured with the MCdeficient strain $(p<0.001)$.

In contrast, the density of the green alga, which was cocultivated with MC-deficient strain, M. aeruginosa PCC 7005, was not significantly different to the control after the first 7 days $(p>0.05)$. Afterwards, the biomass of green alga was decreased significantly and slowly fell to $320 \times$ $10^{4} \pm 13 \times 10^{4}$ cells $\mathrm{mL}^{-1}$ at the end of the co-cultivation experiments on day 14 that was 1.6 times lower than the monoculture $(p<0.001$, Fig. 1a).

The results showed that after 14 days of co-cultivation, the cell density of $M$. aeruginosa 7806 was significantly decreased in mono- ( $\mathrm{C}$ 1) and co-cultures ( $\mathrm{T}$ 1), compared to the 1-month-old monoculture (initial) $(p<0.001$, Fig. 1b). Moreover, the growth of Microcystis in co-culture (T 1) remained unchanged, compared to the simultaneously conducted monoculture (C 1) ( $p>0.05$, Fig. 1b).

\section{Toxin concentration}

At the inception of the experiment in 1-month-old monoculture (initial), the total concentration of extracellular MCLR (inside plus outside the dialysis membrane) was $1050.2 \pm 51.7 \mu \mathrm{g} \mathrm{L}^{-1}$ (Fig. 2a) and the intracellular MC-LR concentration was $1214.5 \pm 114.5 \mu \mathrm{g} \mathrm{g}^{-1}$ (Fig. 2b). After 2 weeks of co-cultivation, the concentration of intracellular MC-LR in mono- (C 1) and co-cultures ( $\mathrm{T}$ 1) remained unchanged compared to the intracellular MC-LR concentration at the start of the experiment (initial) (Fig. 2b, $p>0.05$ ). In contrast, the concentration of extracellular MCLR was significantly raised both with mono- and 


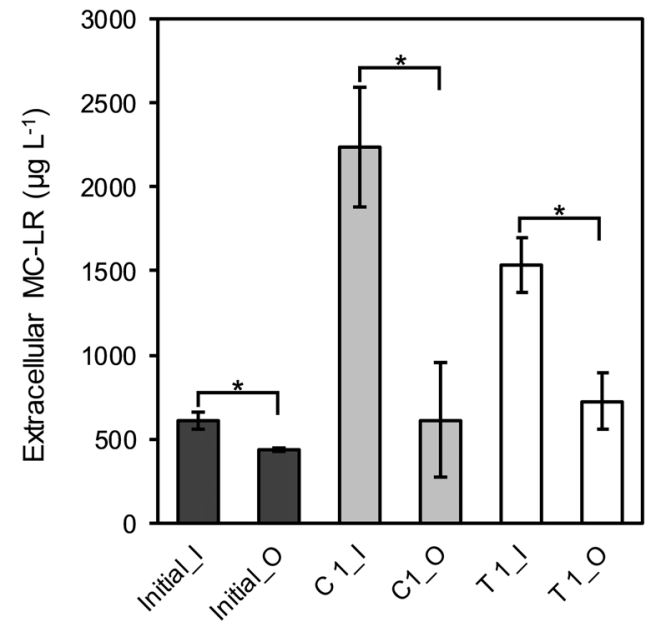

Fig. 3 The concentration of the extracellular MC-LR $\left(\mu \mathrm{g} \mathrm{L}^{-1}\right)$ in the controls and treatment on the inside and outside of the dialysis tubing, measured after 1 month in monoculture (initial) and 6 weeks in monoculture (control 1) and co-culture (treatment 1) of toxic $M$. aeruginosa PCC 7806 (Initial: 1-month-old monoculture, C 1: control 1, T 1: treatment 1 , I: in the dialysis tubing, O: out of the dialysis tubing). Data represent means \pm standard deviation $(n=3)$. Asterisk indicates significant differences at a $p$-value of $p<0.01$

co-cultivation ( $p \leq 0.001$, Fig. 2a). However, after 2 weeks of co-cultivation, the increased MC release in co-culture ( $\mathrm{T}$ 1) was at the same level as the simultaneous monoculture ( $C$ 1) ( $p>0.05$, Fig. 2a). Additionally, the amount of outer membrane extracellular MC-LR that was the actual concentration at which the green alga has been exposed was not significantly different relative to the control (C 1) $(p>0.05$, Fig. 2).

The efficiency of employing the dialysis membrane in the co-cultivation system was assessed in terms of the diffusion rate of MC-LR. This was evaluated by measuring the concentration of extracellular MC-LR at both sides of the dialysis tubing (Fig. 3). The results showed that at the start of the co-cultivation experiment with $M$. aeruginosa PCC7806 monoculture (initial), as well as after 14 days of both mono- (C 1) and co-culture (T 1), the concentration of extracellular MC-LR inside the dialysis membrane was significantly higher than the outer of the membrane $(p<$ 0.01 , Fig. 3). However, in the 1-month-old monoculture (initial) where the lowest concentration of extracellular MCLR was measured, the highest diffusion rate of extracellular MC-LR (0.7) was observed which was at the same level as co-culture ( $\mathrm{T} 1)$ and significantly greater than the monoculture of the co-cultivation experiment (C 1) $(p>0.05$ and $p<0.05$, respectively, Fig. 4). As Microcystis cells were entering the death phase, the release of MC-LR increased due to the increased cell lysis (Fig. 1b) after 2 weeks of co-cultivation. Therefore, the MC was less distributed between the inner and outer side of the dialysis membrane (Figs 3 and 4).

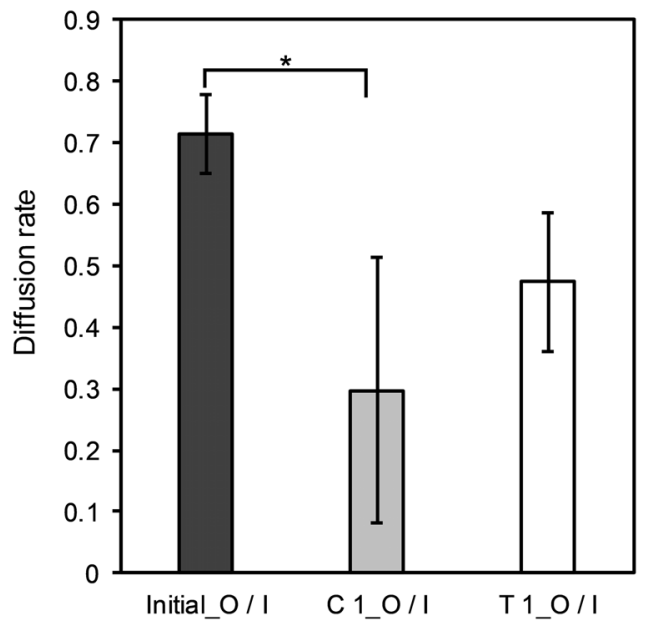

Fig. 4 The diffusion rate of extracellular MC-LR in controls and treatment (Initial: 1-month-old monoculture of $M$. aeruginosa PCC 7806; C 1: control 1, 6 weeks old monoculture of M. aeruginosa PCC 7806; T 1: treatment 1, co-culture of M. aeruginosa PCC 7806 with $D$. subspicatus, I/O: in/out of dialysis tubing). Data represent means \pm standard deviation $(n=3)$. Significant difference observed at a $p$-value of $* p<0.05$

\section{Discussion}

In the present study, a co-cultivation system was designed using a dialysis membrane as a separation technique, where Microcystis strains were grown inside of the dialysis tubing and the green alga was cultured outside of the tubing. The system allowed the species to influence each other through their diffusible extracellular products without any physical cell-cell contacts. Thus, the shading effects of the buoyant Microcystis cells which were grown to a dense culture could be restricted through confining the Microcystis cells inside of the dialysis membrane in the mixed culture. The results showed that over time the extracellular MC-LR diffused through the membrane. However, the diffusion rate of the released MC across the membrane was affected by a sudden large release of extracellular MC-LR, possibly delaying diffusion to achieve an equilibrium on both sides.

The results showed that during the co-cultivation experiment, coinciding with the decreased cell density of $M$. aeruginosa toxic strain in both the control and treatments, the concentration of intracellular MC-LR remained unchanged in mono- and co-cultures. However, the total extracellular MC-LR from both the inside and outside was significantly higher, which can be explained by the Microcystis cells entering into the stationary phase of growth (Lyck 2004; Jähnichen et al. 2008). This means that D. subspicatus which was growing to the exponential phase of growth was exposed to the contents of the Microcystis cells that passed into the collapse phase of growth. The growth of the green alga was inhibited in co-cultivation 
with both toxic and non-toxic strains of Microcystis. However, MC-producing strain inhibited the growth of green alga greater and in earlier days, compared to the MCdeficient strain. Then, it was assumed that the toxic strain might benefit from MC production through outcompeting of the co-existing green alga. Moreover, the green alga showed a longer lag phase in the presence of MC-producing strain compared to the control and MC-deficient Microcystis. The study by Mohamed (2008) indicated that the green algae, Chlorella and Scenedesmus, could absorb and biotransform MCs. The inhibitory effects of MCs on the growth and photosynthesis of the other members of phytoplankton community have been reported in other investigations as well (Singh et al. 2001; Sukenik et al. 2002; Yang et al. 2014). MCs could negatively affect the exposed species through the restriction of the carbonic anhydrase activity (Sukenik et al. 2002), the reduction of $\mathrm{CO}_{2}$ uptake, depletion of nitrogen fixation (Singh et al. 2001), and the induction of oxidative stress that lead to programmed cell death (Pietsch et al. 2001; Pflugmacher 2004; Amado and Monserrat 2010). Therefore, it might be assumed that the green alga needed more time to fix the damages which might have resulted from the presence of MC and/or the other secondary metabolites of Microcystis.

The results indicated that the naturally occurring nontoxic strain of $M$. aeruginosa PCC 7005 negatively influenced the growth of green alga as well. However, it took longer, and the inhibition was significantly smaller than the co-cultures with the wild-type MC-producing strain PCC 7806. Then, the inhibitory effects of Microcystis on the growth of green alga was not only related to MC but also the increased release of the other probable secondary metabolites over time were involved. Previous studies showed the other secondary metabolites of Microcystis such as micropeptin, microviridin, microgenin, as well as some unidentified compounds might interfere in the interspecies interactions (Banker and Carmeli 1999; Reshef and Carmeli 2001; Ploutno et al. 2002). However, the results of the current study showed that the presence of MC might reinforce the inhibitory effects of Microcystis on the growth of the co-existing green alga. More studies need to be done concerning the analysis of the secondary metabolic profile of both MC-producing and -deficient strains, for undoubted confirm or rejection of the probable involvement of the other cyanobacterial metabolites in combination with or rather than $\mathrm{MC}$ in the interspecies interactions.

On the other hand, the green alga did not affect the MC production and release from MC-producing strain that might be related to the population ratio and the physiological status of the co-existing species which influenced the pattern of the algal communications. The study by Bittencourt-Oliveira et al. (2015) showed that at the equal

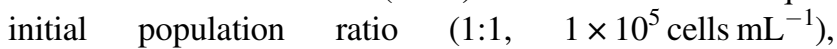

Scenedesmus acuminatus induced MC production in $M$. aeruginosa. The study by Harel et al. (2013) showed that the interspecies interactions between Scenedesmus huji and $M$. aeruginosa spp. at the same initial density of $1 \times 10^{5}$ cells $\mathrm{mL}^{-1}$, was depending on the physiological status of the species. They showed that the metabolites derived from the stationary phase of the growth of green alga, S. huji, caused severe cell lysis in Microcystis spp. through the decrease of the integrity of the cell membrane. The study by Yang et al. (2018) showed M. aeruginosa and Scenedesmus obliquus at the similar algal initial abundance of $1 \times 10^{5}$ cells $\mathrm{mL}^{-1}$ have negatively affected one another's growth at $20-30^{\circ} \mathrm{C}$, depending on their physiological status. As temperature increased from 20 to $30^{\circ} \mathrm{C}$, the competitive advantages of the green alga was decreased where the green alga was superior for a shorter time at the initial phase of cocultivation while towards the end of the co-cultivation period Microcystis resumed dominance in the mixed culture. Moreover, the results indicated that the growth of MCproducing Microcystis was not influenced in the presence of the co-cultured green alga. However, the growth of MCdeficient strain was not monitored. Therefore, due to the lack of enough data it cannot be possible to assume whether the MC-producing strain benefited from MC over the MCdeficient strain to improve its fitness or not.

Taken together with the current study of the interspecies interplay between toxic and non-toxic strains of $M$. aeruginosa and the green alga, the probable importance of MC for the toxic Microcystis is evident. The results indicated that Microcystis, toxic and non-toxic strains, affected the growth of co-cultured green alga negatively. However, the growth inhibition in cocultivation with the toxic Microcystis was significantly greater and occurred in earlier days. Then, in cyanobacterial blooms where toxic and non-toxic strains co-existed, the MC-producing strain may gain the advantage of MC production over non-toxic subpopulations to a greater exclusion of the co-existing species. MCs might play a role in the replacement of green algae with the cyanobacterial blooms at the end of summer.

Acknowledgments This work was supported by Elsa-NeumannScholarship (formally known as NaFöG) from the state of Berlin in the context of the Elsa-Neumann $\mathrm{PhD}$ scholarship. Open access funding was provided by the University of Helsinki, including Helsinki University Central Hospital.

\section{Compliance with ethical standards}

Conflict of interest The authors declare that they have no conflict of interest.

Ethical approval This article does not contain any studies with human participants or animals performed by any of the authors.

Publisher's note: Springer Nature remains neutral with regard to jurisdictional claims in published maps and institutional affiliations. 
Open Access This article is distributed under the terms of the Creative Commons Attribution 4.0 International License (http://crea tivecommons.org/licenses/by/4.0/), which permits unrestricted use, distribution, and reproduction in any medium, provided you give appropriate credit to the original author(s) and the source, provide a link to the Creative Commons license, and indicate if changes were made.

\section{References}

Amado LL, Monserrat JM (2010) Oxidative stress generation by microcystins in aquatic animals: why and how. Environ Int 36:226-235

Banker R, Carmeli S (1999) Inhibitors of serine proteases from a waterbloom of the cyanobacterium Microcystis sp. Tetrahedron 55:10835-10844

Bittencourt-Oliveira M, Chia MA, De Oliveira HSB, Araújo MKC, Molica RJR, Dias CTS (2015) Allelopathic interactions between microcystin-producing and non-microcystin-producing cyanobacteria and green microalgae: implications for microcystins production. J Appl Phycol 27:275-284

Buratti FM, Manganelli M, Vichi S, Stefanelli M, Scardala S, Testai E, Funari E (2017) Cyanotoxins: producing organisms, occurrence, toxicity, mechanism of action and human health toxicological risk evaluation. Arch Toxicol 91:1049-1130

Carmichael W (1992) Cyanobacteria secondary metabolites-the cyanotoxins. J Appl Bacteriol 72:445-459

Catherine Q, Susanna W, Isidora ES, Mark H, Aurelie V, Jean-François $H$ (2013) A review of current knowledge on toxic benthic freshwater cyanobacteria-ecology, toxin production and risk management. Water Res 47:5464-5479

Chen Y, Qin B, Teubner K, Dokulil MT, Catherine Q (2003) Longterm dynamics of phytoplankton assemblages: Microcystis-domination in Lake Taihu, a large shallow lake in China. J Plankton Res 25:445-453

Christiansen G, Molitor C, Philmus B, Kurmayer R, Catherine Q (2008) Nontoxic strains of cyanobacteria are the result of major gene deletion events induced by a transposable element. Mol Biol Evol 25:1695-1704

Christoffersen K, Lyck S, Winding A (2002) Microbial activity and bacterial community structure during degradation of microcystins. Aquat Micro Ecol 27:125-136

Dziallas C, Grossart HP (2011) Increasing oxygen radicals and water temperature select for toxic Microcystis sp. PLoS ONE 6:e25569

El Herry S, Fathalli A, Rejeb AJB, Bouaïcha N, Falconer I (2008) Seasonal occurrence and toxicity of Microcystis spp. and Oscillatoria tenuis in the Lebna Dam, Tunisia. Water Res 42:1263-1273

Gagała I, Mankiewicz-Boczek J (2012) The natural degradation of microcystins (cyanobacterial hepatotoxins) in fresh water-the future of modern treatment systems and water quality improvement. Pol J Environ Stud 21:1125-1139

Granéli E, Hansen PJ (2006) Allelopathy in harmful algae: a mechanism to compete for resources? In: Granéli E, Turner JT (eds) Ecology of harmful algae. Springer-Verlag, Berlin, Heidelberg, p 189-201

Harel M et al. (2013) Interactions between Scenedesmus and Microcystis may be used to clarify the role of secondary metabolites. Environ Microbiol Rep 5:97-104

Jähnichen S, Ihle T, Petzoldt T, Benndorf J, Boynton A (2007) Impact of inorganic carbon availability on microcystin production by Microcystis aeruginosa PCC 7806. Appl Environ Microbiol 73:6994-7002

Jähnichen S, Ihle T, Petzoldt T (2008) Variability of microcystin cell quota: a small model explains dynamics and equilibria. Limnologica 38:339-349
Jones GJ, Orr PT (1994) Release and degradation of microcystin following algicide treatment of a Microcystis aeruginosa bloom in a recreational lake, as determined by HPLC and protein phosphatase inhibition assay. Water Res 28:871-876

Leão PN, Vasconcelos MTS, Vasconcelos VM (2009) Allelopathy in freshwater cyanobacteria. Crit Rev Microbiol 35:271-282

Leflaive J, Ten-Hage L (2007) Algal and cyanobacterial secondary metabolites in freshwaters: a comparison of allelopathic compounds and toxins. Freshw Biol 52:199-214

Legrand C, Rengefors K, Fistarol GO, Graneli E, Boynton A (2003) Allelopathy in phytoplankton-biochemical, ecological and evolutionary aspects. Phycologia 42:406-419

Lévesque B et al. (2014) Prospective study of acute health effects in relation to exposure to cyanobacteria. Sci Total Environ 466:397-403

Lyck S (2004) Simultaneous changes in cell quotas of microcystin, chlorophyll a, protein and carbohydrate during different growth phases of a batch culture experiment with Microcystis aeruginosa. J Plankton Res 26:727-736

Mohamed ZA (2008) Polysaccharides as a protective response against microcystin-induced oxidative stress in Chlorella vulgaris and Scenedesmus quadricauda and their possible significance in the aquatic ecosystem. Ecotoxicology 17:504-516

Nishizawa T, Ueda A, Asayama M, Fujii K, Harada K-i, Ochi K, Shirai M (2000) Polyketide synthase gene coupled to the peptide synthetase module involved in the biosynthesis of the cyclic heptapeptide microcystin. J Biochem 127:779-789

Omidi A, Esterhuizen-Londt M, Pflugmacher S (2017) Still challenging: the ecological function of the cyanobacterial toxin microcystin-What we know so far. Toxin Rev 37:87-105

Paerl HW, Fulton RS, Moisander PH, Dyble J, Boynton A (2001) Harmful freshwater algal blooms, with an emphasis on cyanobacteria. Sci World J 1:76-113

Pflugmacher S (2004) Promotion of oxidative stress in the aquatic macrophyte Ceratophyllum demersum during biotransformation of the cyanobacterial toxin microcystin-LR. Aquat Toxicol 70:169-178

Pietsch C, Wiegand C, Amé MV, Nicklisch A, Wunderlin D, Pflugmacher S (2001) The effects of a cyanobacterial crude extract on different aquatic organisms: evidence for cyanobacterial toxin modulating factors. Environ Toxicol 16:535-542

Ploutno A, Shoshan M, Carmeli S (2002) Three novel protease inhibitors from a natural bloom of the cyanobacterium Microcystis aeruginosa. J Nat Prod 65:973-978

Rapala J, Sivonen K, Lyra C, Niemelä SI (1997) Variation of microcystins, cyanobacterial hepatotoxins, in Anabaena spp. as a function of growth stimuli. Appl Environ Microbiol 63:2206-2212

Renaud SL, Pick FR, Fortin N (2011) The effect of light intensity on the relative dominance of toxigenic and nontoxigenic strains of Microcystis aeruginosa. Appl Environ Microbiol 77:7016-7022

Reshef V, Carmeli S (2001) Protease inhibitors from a water bloom of the cyanobacterium Microcystis aeruginosa. Tetrahedron 57:2885-2894

Reynolds CS (1980) Phytoplankton assemblages and their periodicity in stratifying lake systems. Ecography 3:141-159

Reynolds CS (2006) The ecology of phytoplankton. Cambridge University Press, Cambridge, UK

Rippka R, Deruelles J, Waterbury JB, Herdman M, Stanier RY (1979) Generic assignments, strain histories and properties of pure cultures of cyanobacteria. Microbiology 111:1-61

Scholz SN, Esterhuizen-Londt M, Pflugmacher S (2017) Rise of toxic cyanobacterial blooms in temperate freshwater lakes: causes, correlations and possible countermeasures. Toxicol Environ Chem 99:543-577

Sedmak B, Kosi G (1998) The role of microcystins in heavy cyanobacterial bloom formation. J Plankton Res 20:691-708 
Singh DP, Tyagi M, Kumar A, Thakur J, Kumar A (2001) Antialgal activity of a hepatotoxin-producing cyanobacterium, Microcystis aeruginosa. World J Microbiol Biotechnol 17:15-22

Sivonen K, Jones G (1999) Cyanobacterial toxins. In: Chorus I, Bartram J (eds) Toxic cyanobacteria in water: a guide to their public health consequences, monitoring and management. E \& FN Spon, London, On behalf of the World Health Organization, p 41-111

Sukenik A et al. (2002) Inhibition of growth and photosynthesis of the dinoflagellate Peridinium gatunense by Microcystis sp. (cyanobacteria): a novel allelopathic mechanism. Limnol Oceanogr 47:1656-1663

Svirčev Z, Drobac D, Tokodi N, Mijović B, Codd GA, Meriluoto J (2017) Toxicology of microcystins with reference to cases of human intoxications and epidemiological investigations of exposures to cyanobacteria and cyanotoxins. Arch Toxicol 91:621-650

Turner AD, Dhanji-Rapkova M, O'Neill A, Coates L, Lewis A, Lewis $\mathrm{K}$ (2018) Analysis of microcystins in cyanobacterial blooms from freshwater bodies in England. Toxins 10:39

Vardi A, Schatz D, Beeri K, Motro U, Sukenik A, Levine A, Kaplan A (2002) Dinoflagellate-cyanobacterium communication may determine the composition of phytoplankton assemblage in a mesotrophic lake. Curr Biol 12:1767-1772
Welker M, Von Döhren H (2006) Cyanobacterial peptides-nature's own combinatorial biosynthesis. FEMS Microbiol Rev 30:530-563

World Health Organization (2003) Guidelines for safe recreational water environments: coastal and fresh waters. WHO, Geneva, Switzerland

Yang J, Deng X, Xian Q, Qian X, Li A (2014) Allelopathic effect of Microcystis aeruginosa on Microcystis wesenbergii: microcystinLR as a potential allelochemical. Hydrobiologia 727:65-73

Yang J, Tang H, Zhang X, Zhu X, Huang Y, Yang Z (2018) High temperature and $\mathrm{pH}$ favor Microcystis aeruginosa to outcompete Scenedesmus obliquus. Environ Sci Pollut Res 25:4794-4802

Zanchett G, Oliveira-Filho EC (2013) Cyanobacteria and cyanotoxins: from impacts on aquatic ecosystems and human health to anticarcinogenic effects. Toxins 5:1896-1917

Zhang Y, Jiang HB, Liu SW, Gao KS, Qiu BS (2012) Effects of dissolved inorganic carbon on competition of the bloom-forming cyanobacterium Microcystis aeruginosa with the green alga Chlamydomonas microsphaera. Eur J Phycol 47:1-11

Zhang Y, Wang J, Tan L, Cao J, Li H (2015) Effect of allelopathy on the competition and succession of Skeletonema costatum and Prorocentrum donghaiense. Mar Biol Res 11:1093-1099 